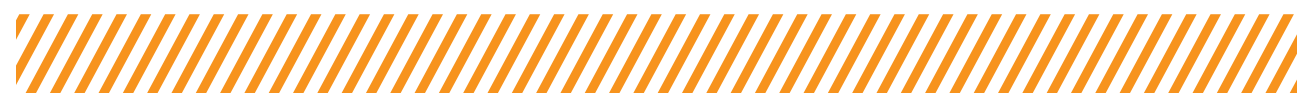

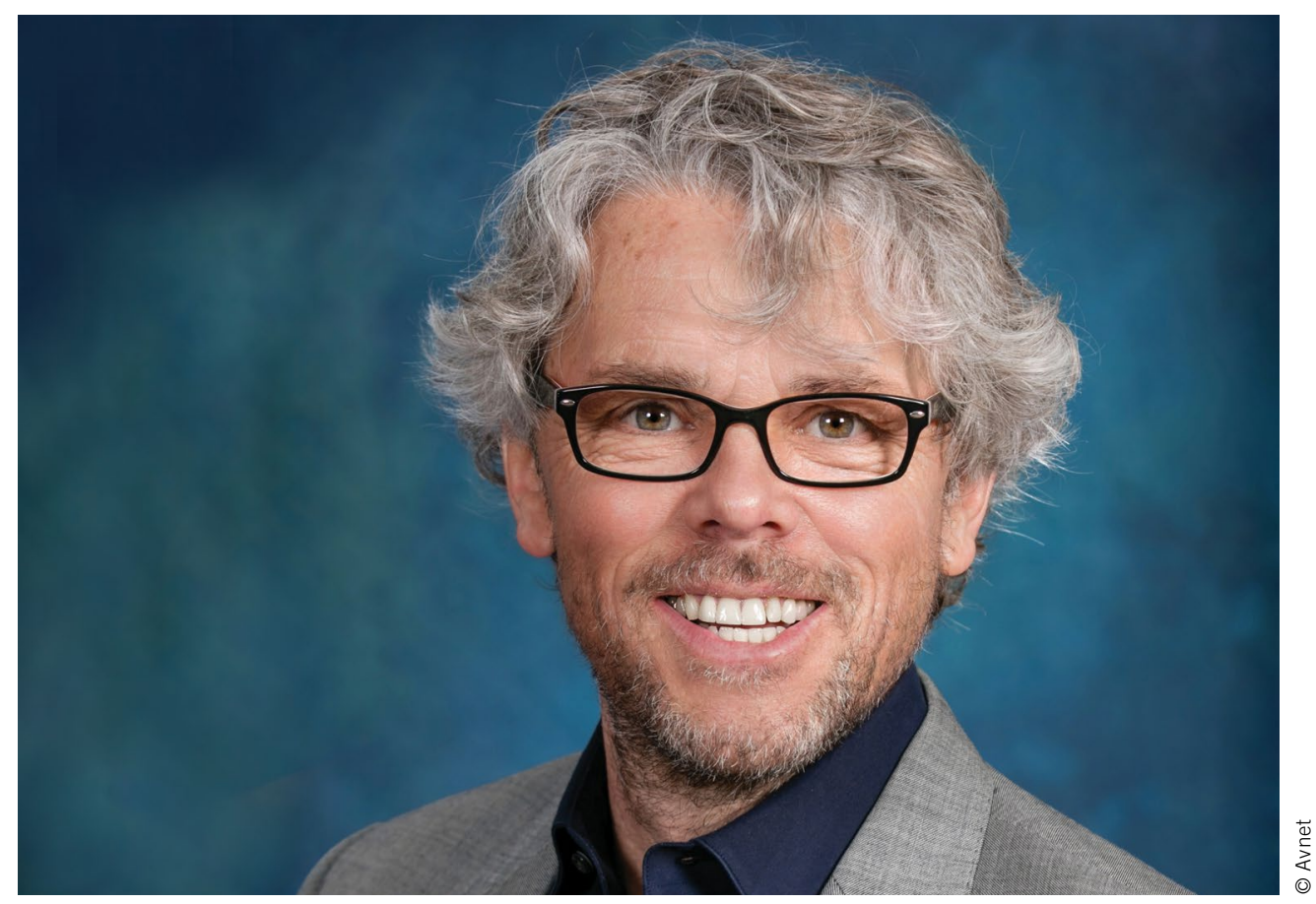

Georg Steinberger

Vice President Communications, Avnet Electronics Marketing EMEA in Poing near Munich

\section{Semiconductors - Scarce but Sexy}

If the TV evening news report on chip shortage and unfinished cars piling up and the EU announces a "Chip act", the situation must be severe. And it is.

Differences to past semiconductor cycles are the mounting geopolitics between USA and China, the strong concentration of market power by chip producers and their big customers, the increasing complexity of flagship products (processors) and the crazy cost of a state-of-the-art wafer fab (20 billion US-dollars). They show the dilemma Europe is facing. Leading semiconductor companies are either American or Korean - and if including the leading foundry TSMC, also Taiwanese. Their focus lies on top-class processors and memories for which giant investments in smallest structures and expensive processes are justified. To date, only Samsung and TSMC can mass-produce devices with $7 \mathrm{~nm}$ or smaller, others, in case they can design devices of that complex nature, buy their manufacturing service. Most semiconductor companies - among them Europeans - don't play in that league. They have devices that need less complex processes.

The mounting conflict between the USA and China puts a spotlight on the role Asia, and particularly Taiwan, are playing for many US semiconductor companies, who primarily use TSMC as their foundry. Soliciting the help of the US government, these companies want to ensure that their products will not only be "fabbed" in Taiwan, but also in the US. Furthermore, the US who dominate intellectual property in the semi world want to keep China out of the semi production supply chain altogether - from chemicals, wafers, equipment to the end packaging of components. From their rather strong position, the US could succeed. Europe lacks such a strength. The semi production supply chain as seen through a European lens is weak and it misses a critical ingredient - intellectual property that goes on chips.

On the demand side - besides some Korean or Chinese companies - US companies dominate as well, with their giant volumes of smartphones, tablets, computers, servers or dominant software and internet services, all of which increase the consumption of semiconductors - Apple, HP, Dell, Google, Amazon etc. They drive innovative chip design and big volumes that are by far out of reach for any European customers or industries. And they display a different procurement behavior, put availability before price to secure capacity.

The European semiconductor market - in 2021 nearly 50 billion US-Dollars and representing less than $10 \%$ of the world market - becomes increasingly a backseat operation for many suppliers. A big US smartphone company provides higher chip revenue for producers than the entirety of Europe. The European industry should remember this when thinking of - predictable future crises to avoid self-inflicted supply problems, at least partially. To master present and future challenges like climate protection, digitization and mobility, the demand for semiconductors will inevitably increase. Any planning process at semi-using customers should define semiconductor demand as top priority. 